\title{
Cytokines and Onchocerciasis-Associated Epilepsy, a Pilot Study and Review of the Literature
}

\author{
Melissa Krizia Vieri ${ }^{1, *(\mathbb{D})}$, An Hotterbeekx ${ }^{1,2}{ }^{\mathbb{D}}$, Stephen Raimon ${ }^{3}$, Gasim Abd-Elfarag ${ }^{4,5}$, Deby Mukendi ${ }^{6,7}$, \\ Jane Y. Carter ${ }^{8}$, Samir Kumar-Singh ${ }^{2}$ and Robert Colebunders ${ }^{1, * \mathbb{D}}$
}

1 Global Health Institute, University of Antwerp, 2610 Antwerp, Belgium; an.hotterbeekx@uantwerpen.be

2 Molecular Pathology Group, Laboratory of Cell Biology \& Histology, Faculty of Medical and Health Sciences, University of Antwerp, 20610 Antwerp, Belgium; samir.kumar-singh@uantwerpen.be

3 Amref Health Africa, Juba P.O. Box 30125, South Sudan; stephenraimon@gmail.com

4 Academic Medical Center, Global Child Health Group, Department of Paediatrics and Department of Global Health, University of Amsterdam, 1105 Amsterdam, The Netherlands; gasim4u83@gmail.com

5 Amsterdam Institute for Global Health and Development, 1105 Amsterdam, The Netherlands

6 Institut National de Recherche Biomédicale, Av. De la Démocratie N5345, Kinshasa 1197, Congo; debymukendi@yahoo.fr

7 Centre Neuro-Psycho Pathologique, Universite' de Kinshasa, Kinshasa P.O. Box 127, Congo

8 Amref International Headquarters, Nairobi P.O. Box 27691-00506, Kenya; jane.carter@amref.org

* Correspondence: krizia.vieri@uantwerpen.be (M.K.V.); robert.colebunders@uantwerpen.be (R.C.); Tel.: +32-3265-2552 (M.K.V.); +32-3265-1804 (R.C.); Fax: +32-3-265-26-63 (R.C.)

check for updates

Citation: Vieri, M.K.; Hotterbeekx, A.; Raimon, S.; Abd-Elfarag, G.; Mukendi,

D.; Carter, J.Y.; Kumar-Singh, S.;

Colebunders, R. Cytokines and

Onchocerciasis-Associated Epilepsy, a

Pilot Study and Review of the

Literature. Pathogens 2021, 10, 310.

https://doi.org/10.3390/

pathogens 10030310

Academic Editor: Fabrizio Bruschi

Received: 4 February 2021

Accepted: 5 March 2021

Published: 7 March 2021

Publisher's Note: MDPI stays neutral with regard to jurisdictional claims in published maps and institutional affiliations.

Copyright: (c) 2021 by the authors. Licensee MDPI, Basel, Switzerland. This article is an open access article distributed under the terms and conditions of the Creative Commons Attribution (CC BY) license (https:/ / creativecommons.org/licenses/by/ $4.0 /)$.
Abstract: Neuro-inflammation may be associated with onchocerciasis-associated epilepsy (OAE) but thus far very few immunological studies have been performed in children with this form of epilepsy. In a pilot study we measured the cytokine levels in cerebrospinal fluid (CSF) of persons with OAE from Maridi, South Sudan, and from Mosango, Democratic Republic of the Congo (DRC) and compared these results with cytokine levels in CSF of Africans with non-OAE neurological disorders, and Europeans with epilepsy or other neurological conditions. The following cytokines were studied: IL-6, TNF- $\alpha$, IL1- $\beta$, IL-5, IL-4, IL-13, CCL3 (Mip-1 $\alpha$ ), VEGF-C, VCAM-1. No cytokine was significantly associated with OAE, although a lower IL-13 level was observed in CSF of persons with OAE compared to African controls. Observed cytokine profiles and neuro-inflammation may be the consequence of long-standing epilepsy, concomitant infections and malnutrition. Ideally cytokine levels should be determined in a prospective study in serum and CSF collected the time of onset of the first seizures.

Keywords: onchocerciasis-associated epilepsy; cerebrospinal fluid; cytokines

\section{Introduction}

Recent studies suggest that nodding syndrome is one of the clinical presentations of an epileptic disorder now called onchocerciasis associated epilepsy (OAE) [1]. OAE is characterised by an onset of epilepsy without any obvious cause between the ages of 3-18 years in previously healthy children in an area of high ongoing or past onchocerciasis transmission [1]. OAE including nodding syndrome disappears when onchocerciasis is eliminated [1,2].

Epidemiological studies suggest that the Onchocerca volvulus parasite is associated with epilepsy but the pathogenesis remains to be elucidated. The skin snip microfilarial (mf) load in children seems to be the main determinant for the risk of developing epilepsy [3,4]. However, $\mathrm{mf}$ are not found in the cerebrospinal fluid (CSF) on a regular basis and have not been shown to penetrate the blood-brain barrier (BBB) [5]. Before the implementation of mass ivermectin administration programs, $\mathrm{mf}$ were detected in the CSF of certain individuals with a high level of $O$. volvulus infection [6], but mf have not been detected in CSF in recent studies $[7,8]$. Another potential mechanism is that $O$. volvulus is able to 
trigger an immunological mechanism that may cause brain inflammation or auto-immune disease [9]. It has been hypothesized that leiomodin-1 antibodies cross-reacting with $O$. volvulus proteins may be neurotoxic and induce nodding syndrome [9] but this hypothesis has not been confirmed. A post-mortem study of five persons who died with nodding syndrome in Uganda suggested that nodding syndrome is a tauopathy, a type of neurodegenerative disease [10]; However, in a more recent post-mortem study on nine persons who died with OAE, including five with nodding syndrome, tau deposits were not found in the brains of two individuals and very sparse in two other individuals [5]. Tau deposits have also been described in persons with refractory epilepsy [11], and therefore the tau deposits in persons with OAE are most likely the consequence of repetitive seizures. This second post-mortem study showed localized signs of neuro-inflammation characterized by gliosis and features of past ventriculitis and/or meningitis in all but one participant [5].

Thus far, only three studies have measured cytokine levels in persons with OAE, including nodding syndrome. In a case control study in an onchocerciasis-endemic area in Kasangulu in the Bas-Congo province of DRC, 12 persons with epilepsy and 13 healthy controls were enrolled [12]. Serum cytokines and chemokines were measured using a Luminex multiplex assay. Epilepsy was associated with high serum levels of IL-17, low levels of IL-1RA, and IL-8 [12]. The mean levels of IL-17 and IL-8 in persons with epilepsy were $2.30 \pm 0.98 \mathrm{pg} / \mathrm{mL}$ and $3.07 \pm 0.79 \mathrm{pg} / \mathrm{mL}$, respectively, compared to $1.54 \pm 0.54 \mathrm{pg} / \mathrm{mL}$ and $3.92 \pm 1.07 \mathrm{pg} / \mathrm{mL}$ in healthy controls $(p<0.05)$.

In a second case control study from South Sudan, 20 children with nodding syndrome and 10 healthy controls were enrolled [13]. Cytokines were also measured using the Luminex multiplex assay. The authors of this study reported a $85-99 \%$ reduction of cytokines IL-1 $\beta$, IL-2, IL-6, IL-8, TNF $\alpha$ and IFN $\gamma$ in children with nodding syndrome compared to healthy subjects [13]. However, the results of this study need to be interpreted with caution as in this study extremely high cytokines were also reported in healthy controls. For example, IL-8 levels in healthy individuals were reported as $6840 \pm 754 \mathrm{pg} / \mathrm{mL}$ compared to only $3.92 \pm 1.07 \mathrm{pg} / \mathrm{mL}$ in the previous study in the DRC. The IL-8 cytokine levels from the DRC were only slightly lower than IL-8 levels reported in a study among European children $(9.06 \mathrm{pg} / \mathrm{mL})$ [14]. We speculate that the high cytokine levels observed in the samples from South Sudan may have been the consequence of problem in the way the samples were collected, stored, transported or processed.

A recent case control study conducted in Uganda compared 154 persons with longstanding nodding syndrome and 154 community controls by measuring plasma levels of cytokines, chemokines and complement activation (C5a) markers using ELISA or a custom MagPix Luminex assay. Cytokine CSF levels of the 154 persons with nodding syndrome were also compared with CSF cytokine levels of 15 Ugandan children in remission from a haematological malignancy [15]. No specific cytokines profiles was observe in the CSF of the Ugandan children. However, they were all receiving symptomatic therapy including antiepileptic drugs and bi-annual ivermectin treatment.

With the aim of identifying a cytokine profile that could provide further information for pathology studies in persons with OAE, we tested CSF samples of ivermectin-naïve persons with OAE from South Sudan using a select panel of 9 inflammatory cytokines and chemokines, based on pro-inflammatory (Th1), anti-inflammatory (Th2) and vascularisation response (IL-6, TNF- $\alpha$, IL1- $\beta$, IL-5, IL-4, IL-13,CCL3 (Mip1- $\alpha$ ), VEGF-C, VCAM-1). IL-4, IL-6, IL-13 are type 2 responses playing a critical role in both inflammation and protective immunity [16]. IL-6 is required for protective immune responses against early filarial infection [17]. TNF $\alpha$ and IL1- $\beta$ have been suggested as epilepsy markers [18] while VEGF-C and VCAM-1 are vascularization markers

In the current paper, we present the data of our pilot study and compare them with the results of the studies conducted in the DRC and Uganda. 


\section{Results}

We were unable to identify any characteristic cytokine profile in the CSF of persons with OAE. Only a decreased expression of IL-13 in the CSF of persons with OAE compared to African controls was noted, $p=0.028$ (Figure 1A). IL-6, IL-4 or TNF- $\alpha$ could not be detected, either in cases or controls. A higher level of IL1- $\beta$ was observed in Africans with non-OAE neurological disorders compared to Europeans with epilepsy, $p=0.026$ (Figure 1B). No significant difference was observe within the 4 groups for IL-5 and CCL3 (Mip1- $\alpha$ ) (Figure 1C,D). We did observe a significant different in the expression profile of VVCAM between African controls and Europeans with neurological conditions but no Epilepsy (Figure 2A). However, we did not observe any difference between cases and controls. In addition, no differences was observed among all the groups for the expression of VEGF-C, $p=0.022$ (Figure 2B).
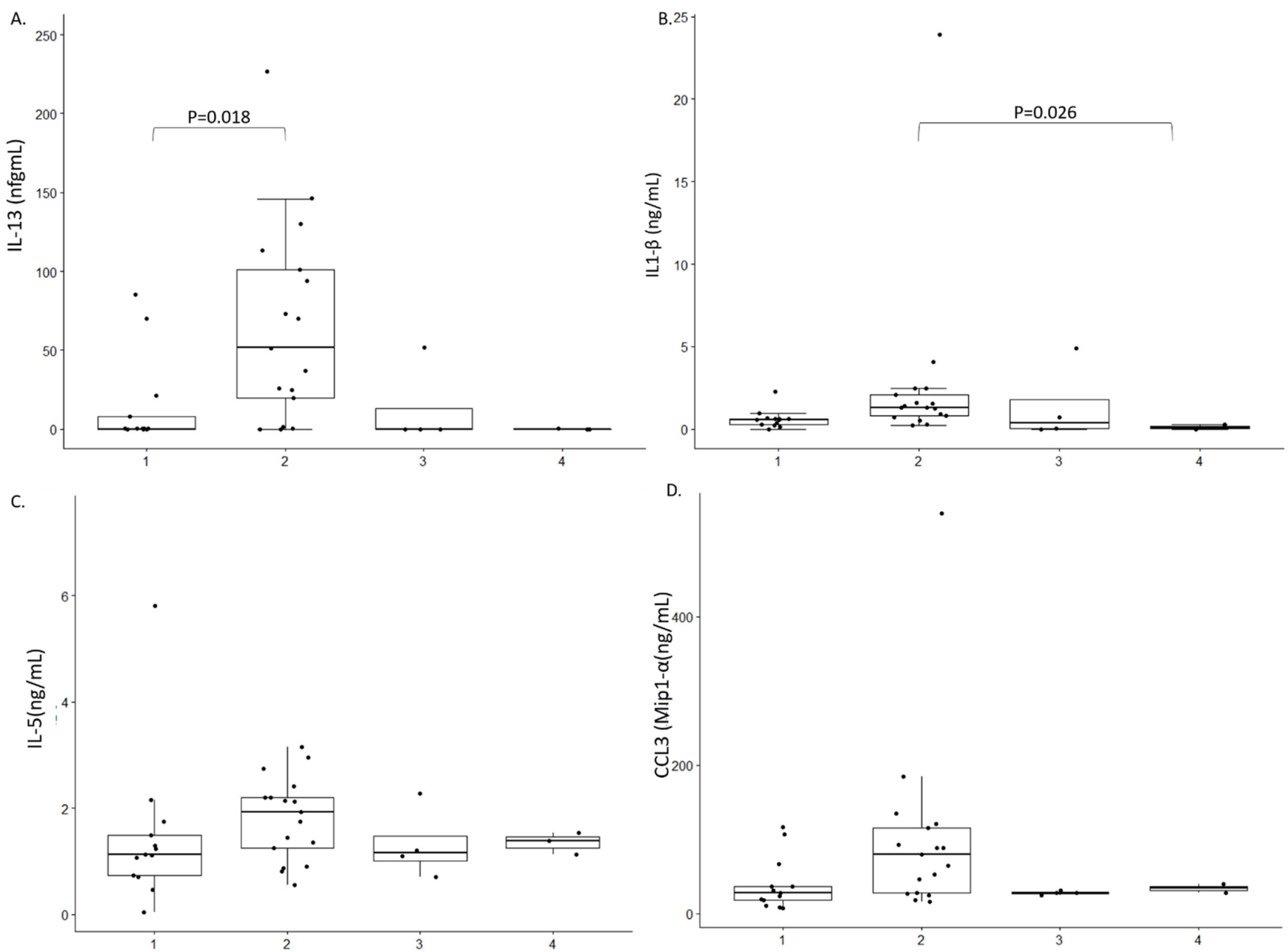

Figure 1. Cytokine expression profile in the study population. 1: Persons with OAE 2: African controls 3: Europeans with a neurological condition but no epilepsy 4: Europeans with epilepsy. Only difference between 2 groups with a $p$-value $<0.05$ are shown. (A). IL-13 expression in $\mathrm{ng} / \mathrm{mL}$; (B). Il-1 $\beta$ expression in $\mathrm{ng} / \mathrm{mL}$; (C) IL-5 expression in ng/mL; (D). CCL3 expression in $\mathrm{ng} / \mathrm{mL}$. 

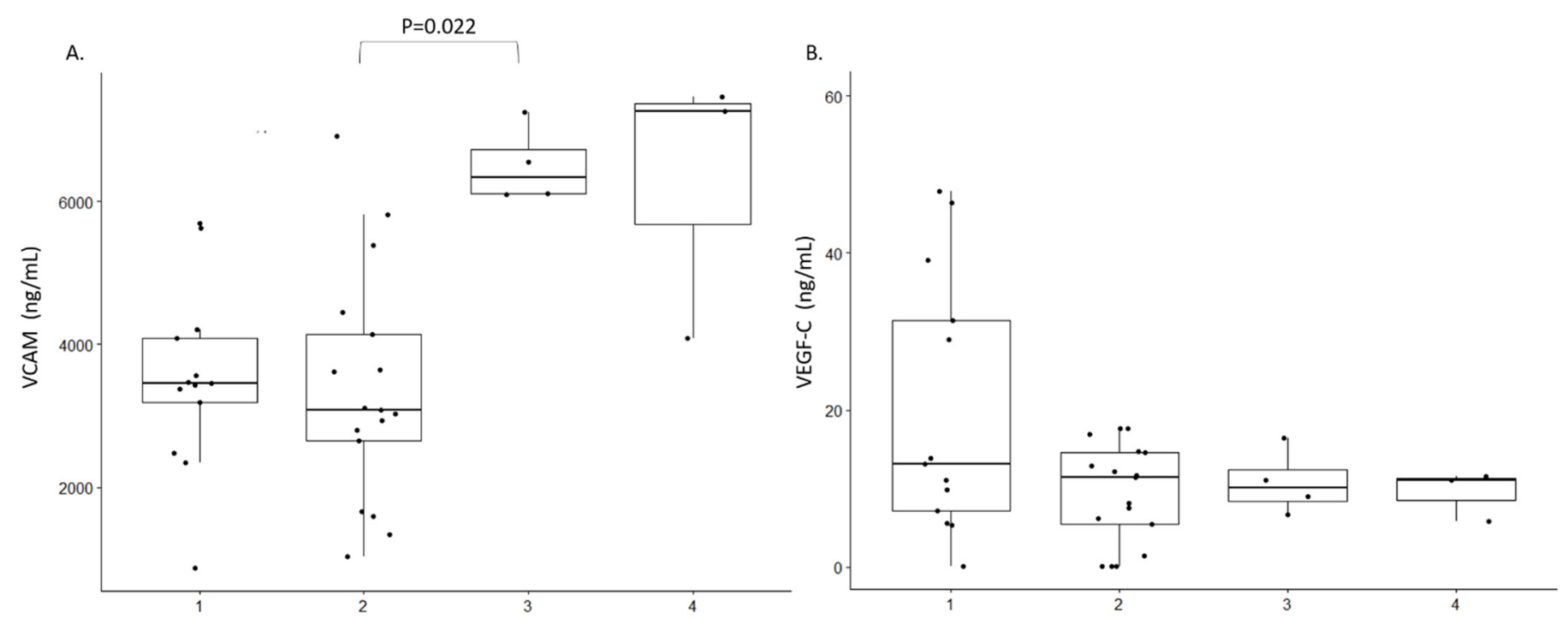

Figure 2. Vascularisation factor expression profile in the study population. 1: Persons with OAE 2: African controls 3: Europeans with a neurological condition but no epilepsy 4: Europeans with epilepsy. Only difference between 2 groups with a $p$-value $<0.05$ are shown. (A). VCAM expression in $\mathrm{ng} / \mathrm{mL}$; (B). VEGF-C expressions in $\mathrm{ng} / \mathrm{mL}$.

\section{Discussion}

In this small pilot study of 13 persons with OAE, we did not observe any characteristic CSF cytokine profile. Nevertheless, we noted a decreased level of IL-13 in the CSF of persons with OAE compared to African controls. A higher level of IL1- $\beta$ was observed in African controls with non-OAE neurological disorders compared to Europeans with epilepsy. We also observed a high level of VCAM in African controls with non OAE compared to Europeans with neurological conditions. However, given the small sample size of the study and without results from cytokine serum levels it is difficult to interpret these results.

In the case control study in Uganda, C5a in CSF and CRP in plasma of children with nodding syndrome was elevated compared to controls. Moreover, the plasma level of CRP correlated with disease severity. Complement activation is associated with neurological conditions including epilepsy, psychiatric disorders and neurodegenerative disorders $[19,20]$. In addition, a decreased level of IL-10, IL-13 CXCL-10 (IP-10), CXCL-13 (BCA-1), CCL-2 (MCP1) and a TNF ligand superfamily member APRIL in plasma was observed [15]. The explanation of these decreased cytokine levels in children with nodding syndrome is unclear but similar decreases in Th-2 type responses have been observed in individuals with prolonged occult $O$. volvulus infection [21] and persons with onchocerciasis with a high $\mathrm{mf}$ load [22]. CXCL-10, CCL-2 and mainly CXCL-13 are good predictor of neuroinflammation in CSF of children [23].

Levels of CXCL9 (MIG), CCL5 (RANTES), IL13, IL6, TNF $\alpha$, MMP-9 and INF $\gamma$ in CSF were comparable between cases and controls. In contrast to our results, IL-13 was not detectable in CSF from children with nodding syndrome. Similar to our study, IL-6 and TNF $\alpha$ was also not detectable in CSF. In contrast to our pilot study and the Ugandan children were al treated ivermectin and anti-epileptic drugs. It has been reported that ivermectin may influence the cytokine profile in persons with O. volvulus infection [24].

The interpretation of cytokine levels in persons with OAE is difficult because an associated O. volvulus infection may also influence cytokine levels. Helminth infections induce the production of type 2 cytokines which lead to both expulsion of the parasite and an inflammatory response. Moreover, elevated cytokine levels have also been observed in different forms of epilepsy [25]. For example, cytokines such as IL-1 $\beta$ and IL-8 have been reported to induce epileptic seizures by activating the cytokine cascade [26]. 


\section{Materials and Methods}

Persons with OAE were selected among participants from previously described studies in South Sudan [27] and the DRC [28]. Characteristics of the study participants are shown in Table 1. Eleven persons with OAE from Maridi in South Sudan were part of a series of 13 persons with OAE with more than 80 O. volvulus $\mathrm{mf}$ counts in their skin snips and in whom a lumbar puncture had been performed at Maridi State Hospital. CSF had been stored immediately at $-20^{\circ} \mathrm{C}$ before being shipped using the cold chain to the University of Antwerp, Belgium. At the University of Antwerp, the CSF was examined for the presence of $O$. volvulus $\mathrm{mf}$, and O. volvulus and Wolbachia DNA but in none was evidence of O. volvulus or Wolbachia infection found [8].

Table 1. Characteristics of 13 persons with OAE (11 from Maridi, South Sudan and two from Mosango, DRC *).

\begin{tabular}{|c|c|c|c|c|c|c|c|c|c|c|}
\hline No. & $\begin{array}{l}\text { Age } \\
\text { (Years) }\end{array}$ & Sex & $\begin{array}{c}\text { ASO } \\
\text { (Years) }\end{array}$ & $\begin{array}{c}\text { Seizure } \\
\text { Frequency } \\
\text { (Monthly) }\end{array}$ & $\begin{array}{c}\text { Generalized } \\
\text { TCS }\end{array}$ & NS & $\begin{array}{c}\text { Mf } \\
\text { Density } \\
\text { (Per SS) }\end{array}$ & $\begin{array}{l}\text { Cognitive } \\
\text { Impairment }\end{array}$ & $\begin{array}{l}\text { Onchocerca } \\
\text { Skin Lesion }\end{array}$ & $\begin{array}{l}\text { Muscle } \\
\text { Wasting }\end{array}$ \\
\hline 1 & 17 & $\mathrm{~F}$ & 14 & 1 & YES & NO & 99.5 & $\mathrm{NO}$ & $\mathrm{NO}$ & $\mathrm{NO}$ \\
\hline 2 & 11 & M & 5 & 150 & YES & YES & 122 & YES & YES & YES \\
\hline 3 & 18 & $M$ & 6 & 120 & YES & YES & 117 & YES & YES & YES \\
\hline 4 & 9 & $M$ & 7 & 120 & YES & YES & 84 & YES & YES & YES \\
\hline 5 & 16 & M & 4 & 90 & YES & YES & 86 & YES & YES & YES \\
\hline 6 & 28 & $\mathrm{~F}$ & 1 & $<1$ & $\mathrm{NO}$ & $\mathrm{NO}$ & 118.5 & $\mathrm{NO}$ & $\mathrm{NO}$ & $\mathrm{NO}$ \\
\hline 7 & 12 & $M$ & 10 & 4 & $\mathrm{NO}$ & YES & 102 & $\mathrm{NO}$ & $\mathrm{NO}$ & $\mathrm{NO}$ \\
\hline 8 & 15 & $\mathrm{~F}$ & 7 & 24 & YES & YES & 85 & $\mathrm{NO}$ & YES & $\mathrm{NO}$ \\
\hline 9 & 19 & $\mathrm{~F}$ & 15 & 12 & YES & YES & 110 & $\mathrm{NO}$ & $\mathrm{NO}$ & $\mathrm{NO}$ \\
\hline 10 & 11 & $\mathrm{~F}$ & 5 & 8 & YES & $\mathrm{NO}$ & 105 & $\mathrm{NO}$ & $\mathrm{NO}$ & $\mathrm{NO}$ \\
\hline 11 & 24 & M & 14 & 90 & $\mathrm{NO}$ & $\mathrm{NO}$ & 108 & $\mathrm{NO}$ & $\mathrm{NO}$ & $\mathrm{NO}$ \\
\hline $12 *$ & 8 & $\mathrm{M}$ & NK & NK & NK & NK & NK & NK & NK & NK \\
\hline $13 *$ & 28 & $\mathrm{~F}$ & NK & NK & NK & NK & NK & NK & NK & NK \\
\hline
\end{tabular}

$\mathrm{ASO}=$ age of seizure onset, $\mathrm{TCS}=$ tonic-clonic seizures, NS = nodding seizures, $\mathrm{Mf}=$ microfilarial load, $\mathrm{SS}=\mathrm{skin}$ snip, $\mathrm{NK}=\mathrm{not} \mathrm{known}$.

Two persons with OAE and 17 African controls with non-OAE neurological disorders were selected from the project "Better Diagnosis for Infectious Diseases" (NIDIAG study) in Mosango, Kwilu Province in the DRC. In that study, consecutive patients with recentonset neurological disorders admitted to Mosango General Referral Hospital had been recruited between 2012 and 2015 [28]. None of the OAE cases received neither ivermectin nor anti-epileptic drugs. Blood and CSF samples were stored at $-80^{\circ} \mathrm{C}$ until analysis.

Stored CSF from the following European controls was also tested: seven persons with epilepsy, four persons with another neurological disorder such as dementia, multiple sclerosis, meningitis, Parkinson's disease.

\subsection{MSD Neuro-Inflammatory Panel}

The following cytokines were coated on the wells of a meso-scale discovery (MSD) custom plate: IL-6, TNF- $\alpha$, IL1- $\beta$, IL-5, IL-4, IL-13, CCL3 (Mip-1 $\alpha$ ), VEGF-C, VCAM-1.

\subsection{Statistical Analysis}

Data were processed and analysed using IBM SPSS statistics. Differences between the different groups were calculated using Kruskal-Wallis test and if this was significant, pairwise comparison was performed using a Bonferroni correction. $p$-values below 0.05 were considered significant. 


\subsection{Litterature Review}

To review the literature, we searched for articles indexed in PubMed and Google scholar up to 31 January 2021. Search terms included "cytokines", "nodding syndrome", "epilepsy and onchocerciasis", "immune response".

\section{Conclusions}

In conclusion, based on the results of our pilot study and review of the literature, it is not possible to determine the causative role of neuro-inflammation in OAE including nodding syndrome. Observed cytokine profiles may be the consequence of long standing epilepsy, concomitant infections and malnutrition. Ideally cytokine levels should be determined in a prospective study, and serum and CSF should be examined at the time of onset of the first seizures.

Author Contributions: Conceptualization M.K.V., A.H., S.K.-S., R.C.; methodology, M.K.V., A.H. and R.C.; software, A.H.; validation, A.H. and R.C.; formal analysis, M.K.V.; investigation, M.K.V. and A.H., S.R., G.A.-E. and D.M.; resources, R.C.; data curation, A.H.; writing—original draft preparation, M.K.V. and R.C.; writing-review and editing, M.K.V., A.H., S.R., G.A.-E., D.M., J.Y.C., S.K.-S. and R.C.; visualization, M.K.V. and A.H.; supervision, R.C.; project administration, R.C.; funding acquisition, R.C. All authors have read and agreed to the published version of the manuscript.

Funding: The study was funded by a grant from the European Research Council (ERC 671055). The study sponsor was not involved in performing the research nor in the writing of the paper.

Institutional Review Board Statement: The study was conducted according to the guidelines of the Declaration of Helsinki, and approved by the ethics committee of the University hospital Antwerp (24 May 2017, B300201733011), the Institutional Review Board of the Institute of Tropical Medicine of Antwerp, Belgium, the ethics committee of the School of Public Health of the University of Kinshasa (28 February 2018, ESP/CE/013/2018), DRC, and the ethics committee of the Ministry of Health, South Sudan.

Informed Consent Statement: All participants were asked to sign an informed consent form and only consenting individuals were enrolled. Minors $>12$ years and $<18$ years signed an assent form in addition, while parents or legal guardians consented for younger participants. All individual data were encoded and treated confidentially.

Data Availability Statement: The datasets generated during the current study are available from the corresponding authors on reasonable request.

Acknowledgments: We thank Kristien Verdonck Abozer Suliman for their collaboration and providing samples. We also thank the PWE and their families for their participation in the study.

Conflicts of Interest: The authors declare no conflict of interest.

\section{References}

1. Colebunders, R.; Njamnshi, A.K.; Menon, S.; Newton, C.R.; Hotterbeekx, A.; Preux, P.-M.; Hopkins, A.; Vaillant, M.; Fodjo, J.N.S. Onchocerca volvulus and epilepsy: A comprehensive review using the Bradford Hill criteria for causation. PLoS Neglected Trop. Dis. 2021, 15, e0008965. [CrossRef]

2. Gumisiriza, N.K.C.; Asaba, G.; Onen, H.; Mubiru, F.; Kisembo, D.; Fodjo, J.N.S.; Colebunders, R. Onchocerciasis elimination drastically reduces epilepsy prevalence and incidence in Kabarole, Western Uganda. In Proceedings of the 4th African Epilepsy Conference, Entebbe, Uganda, 22-24 August 2019.

3. Chesnais, C.B.; Nana-Djeunga, H.C.; Njamnshi, A.K.; Lenou-Nanga, C.G.; Boullé, C.; Bissek, A.-C.Z.-K.; Kamgno, J.; Colebunders, R.; Boussinesq, M. The temporal relationship between onchocerciasis and epilepsy: A population-based cohort study. Lancet Infect. Dis. 2018, 18, 1278-1286. [CrossRef]

4. Chesnais, C.B.; Bizet, C.; Campillo, J.T.; Njamnshi, W.Y.; Bopda, J.; Nwane, P.; Pion, S.D.; Njamnshi, A.K.; Boussinesq, M. A Second Population-based cohort study in cameroon confirms the temporal relationship between onchocerciasis and epilepsy. Open Forum Infect. Dis. 2020, 7, ofaa206. [CrossRef]

5. Hotterbeekx, A.; Lammens, M.; Idro, R.; Akun, P.R.; Lukande, R.; Akena, G.; Nath, A.; Taylor, J.; Olwa, F.; Kumar-Singh, S.; et al. Neuroinflammation and not tauopathy is a predominant pathological signature of nodding syndrome. J. Neuropathol. Exp. Neurol. 2019, 78, 1049-1058. [CrossRef] [PubMed] 
6. Duke, B.O.; Vincelette, J.; Moore, P.J. Microfilariae in the cerebrospinal fluid, and neurological complications, during treatment of onchocerciasis with diethylcarbamazine. Trop. Parasitol. 1976, 27, 123-132. [CrossRef]

7. König, R.; Nassri, A.; Meindl, M.; Matuja, W.; Kidunda, A.R.; Siegmund, V.; Bretzel, G.; Löscher, T.; Jilek-Aall, L.; Schmutzhard, E.; et al. The role of Onchocerca volvulusin the development of epilepsy in a rural area of Tanzania. Parasitology 2010, 137, 1559-1568. [CrossRef]

8. Hotterbeekx, A.; Raimon, S.; Abd-Elfarag, G.; Carter, J.Y.; Sebit, W.; Suliman, A.; Fodjo, J.N.S.; De Witte, P.; Logora, M.Y.; Colebunders, R.; et al. Onchocerca volvulus is not detected in the cerebrospinal fluid of persons with onchocerciasis-associated epilepsy. Int. J. Infect. Dis. 2020, 91, 119-123. [CrossRef] [PubMed]

9. Johnson, T.P.; Tyagi, R.; Lee, P.R.; Lee, M.-H.; Johnson, K.R.; Kowalak, J.; Elkahloun, A.; Medynets, M.; Hategan, A.; Kubofcik, J.; et al. Nodding syndrome may be an autoimmune reaction to the parasitic worm Onchocerca volvulus. Sci. Transl. Med. 2017, 9, eaaf6953. [CrossRef] [PubMed]

10. Pollanen, M.S.; Onzivua, S.; Robertson, J.; McKeever, P.M.; Olawa, F.; Kitara, D.L.; Fong, A. Nodding syndrome in Uganda is a tauopathy. Acta Neuropathol. 2018, 136, 691-697. [CrossRef] [PubMed]

11. Tai, X.Y.; Koepp, M.; Duncan, J.S.; Fox, N.; Thompson, P.; Baxendale, S.; Liu, J.Y.W.; Reeves, C.; Michalak, Z.; Thom, M. Hyperphosphorylated tau in patients with refractory epilepsy correlates with cognitive decline: A study of temporal lobe resections. Brain 2016, 139, 2441-2455. [CrossRef]

12. Burfeind, K.G.; Kashama, J.-M.K.; Bora, B.K.; Murchison, C.F.; Ramos-Crawford, A.L.; Nseka, M.T.; Kunyu, S.B.; Okitundu, D.L.; Mashukano, N.L.; Banea, J.-P.M.; et al. Baseline characterization of epilepsy in an onchocerciasis endemic area of the Democratic Republic of Congo. Brain Res. Bull. 2019, 145, 45-52. [CrossRef]

13. Levite, M.; Zelig, D.; Friedman, A.; Ilouz, N.; Eilam, R.; Bromberg, Z.; Lasu, A.A.R.; Arbel-Alon, S.; Edvardson, S.; Tarshish, M.; et al. Dual-Targeted Autoimmune Sword in Fatal Epilepsy: Patient's glutamate receptor AMPA GluR3B peptide autoimmune antibodies bind, induce Reactive Oxygen Species (ROS) in, and kill both human neural cells and T cells. J. Autoimmun. 2020, 112, 102462. [CrossRef]

14. Mărginean, C.O.; Man, L.; Pitea, A.M.; Man, A.; Mărginean, C.L.; Cotoi, O.S. The assessment between IL-6 and IL-8 and anthropometric status in malnourished children. Rom. J. Morphol. Embryol. 2013, 54, 935-938. [PubMed]

15. Ogwang, R.; Muhanguzi, D.; Mwikali, K.; Anguzu, R.; Kubofcik, J.; Nutman, T.B.; Taylor, M.; Newton, C.R.; Vincent, A.; Conroy, A.L.; et al. Systemic and cerebrospinal fluid immune and complement activation in Ugandan children and adolescents with long-standing nodding syndrome: A case-control study. Epilepsia Open 2020. [CrossRef]

16. Finkelman, F.D.; Wynn, T.A.; Donaldson, D.D.; Urban, J.F. The role of IL-13 in helminth-induced inflammation and protective immunity against nematode infections. Curr. Opin. Immunol. 1999, 11, 420-426. [CrossRef]

17. Muhsin, M.; Ajendra, J.; Gentil, K.; Berbudi, A.; Neumann, A.-L.; Klaas, L.; Schmidt, K.E.; Hoerauf, A.; Hübner, M.P. IL-6 is required for protective immune responses against early filarial infection. Int. J. Parasitol. 2018, 48, 925-935. [CrossRef]

18. Kamaşak, T.; Dilber, B.; Yaman, S.; Durgut, B.D.; Kurt, T.; Çoban, E.; Arslan, E.A.; Şahin, S.; Karahan, S.C.; Cansu, A. HMGB-1, TLR4, IL-1R1, TNF- $\alpha$, and IL-1 $\beta$ : Novel epilepsy markers? Epileptic Disord 2020, 22, 183-193. [CrossRef]

19. Hernandez, M.X.; Namiranian, P.; Nguyen, E.; Fonseca, M.I.; Tenner, A.J. C5a increases the injury to primary neurons elicited by fibrillar amyloid beta. ASN Neuro 2017, 9, 1759091416687871. [CrossRef]

20. Morgan, B.P. The role of complement in neurological and neuropsychiatric diseases. Expert Rev. Clin. Immunol. 2015, 11, 1109-1119. [CrossRef] [PubMed]

21. Meri, T.; Bialonski, A.; Jokiranta, T.S.; Hellwage, J.; Zipfel, P.F.; Meri, S. Onchocerca volvulus microfilariae avoid complement attack by direct binding of factor H. J. Infect. Dis. 2002, 185, 1786-1793. [CrossRef] [PubMed]

22. Brattig, N.W.; Lepping, B.; Timmann, C.; Büttner, D.W.; Marfo, Y.; Hamelmann, C.; Horstmann, R.D. Onchocerca volvulusexposed persons fail to produce interferon- $\gamma$ in response to O. volvulus antigen but mount proliferative responses with interleukin5 and IL-13 production that decrease with increasing microfilarial density. J. Infect. Dis. 2002, 185, 1148-1154. [CrossRef] [PubMed]

23. Liba, Z.; Nohejlova, H.; Capek, V.; Krsek, P.; Sediva, A.; Kayserova, J. Utility of chemokines CCL2, CXCL8, 10 and 13 and interleukin 6 in the pediatric cohort for the recognition of neuroinflammation and in the context of traditional cerebrospinal fluid neuroinflammatory biomarkers. PLoS ONE 2019, 14, e219987. [CrossRef]

24. Mai, C.S.; Hamm, D.M.; Banla, M.; Agossou, A.; Schulz-Key, H.; Heuschkel, C.; Soboslay, P.T. Onchocerca volvulus-specific antibody and cytokine responses in onchocerciasis patients after 16 years of repeated ivermectin therapy. Clin. Exp. Immunol. 2007, 147, 504-512. [CrossRef]

25. De Vries, E.E.; van den Munckhof, B.; Braun, K.P.; van Royen-Kerkhof, A.; de Jager, W.; Jansen, F.E. Inflammatory mediators in human epilepsy: A systematic review and meta-analysis. Neurosci. Biobehav. Rev. 2016, 63, 177-190. [CrossRef]

26. Youn, Y.; Sung, I.K.; Lee, I.G. The role of cytokines in seizures: Interleukin (IL)-1 $\beta$, IL-1Ra, IL-8, and IL-10. Korean J. Pediatr. 2013, 56, 271-274. [CrossRef] [PubMed]

27. Hotterbeekx, A.; Dusabimana, A.; Mandro, M.; Abhafule, G.M.; Deogratias, W.; Fodjo, J.N.S.; Abrams, S.; Colebunders, R. Urinary N-acetyltyramine-O, $\beta$-glucuronide in persons with onchocerciasis-associated Epilepsy. Pathogens 2020, 9, 191. [CrossRef]

28. Mukendi, D.; Tepage, F.; Akonda, I.; Siewe, J.N.F.; Rotsaert, A.; Ndibmun, C.N.; Laudisoit, A.; Couvreur, S.; Kabutako, B.; Menon, S.; et al. High prevalence of epilepsy in an onchocerciasis endemic health zone in the Democratic Republic of the Congo, despite 14 years of community-directed treatment with ivermectin: A mixed-method assessment. Int. J. Infect. Dis. 2019, 79, 187-194. [CrossRef] [PubMed] 